\title{
Allocating limited water: linking ecology and economics
}

\author{
$\underline{\text { R.J. Farquharson }}$, J.W. Freebairn ${ }^{\mathrm{b}}$, J.A. Webb ${ }^{\mathrm{c}}$, M.J. Stewardson ${ }^{\mathrm{c}}$ and T. Ramilan ${ }^{\mathrm{a}, \mathrm{d}}$ \\ ${ }^{a}$ Faculty of Veterinary and Agricultural Sciences, The University of Melbourne, Parkville, Victoria, \\ Australia \\ ${ }^{b}$ Faculty of Business and Economics, The University of Melbourne, Parkville, Victoria, Australia \\ ${ }^{c}$ Department of Infrastructure Engineering, The University of Melbourne, Parkville, Victoria, Australia \\ ${ }^{d}$ International Crops Research Institute for the Semi-Arid Tropics, Patancheru, India \\ Email: bob.farquharson@unimelb.edu.au
}

\begin{abstract}
Available water is limited in quantity with many potentially competing uses, including irrigation, environmental amenity and domestic supply. A question is how to allocate a limited water quantity to different uses for society. Economically we allocate water to equate marginal social benefits across different uses. For environmental amenity this framework relies on ecological response functions and prices. The economic framework uses prices to represent social welfare - representing social willingness to pay for extra ecological amenity. Valuation (pricing) of ecological improvements involves non-market valuation; estimates are available for ecological amenity improvements.
\end{abstract}

An economic decision framework for environmental water requires flow regimes (the decision variable) on the x-axis and ecological responses or endpoints (e.g. for Golden Perch in the Goulburn River) on the y-axis. This analysis characterises the ecological response functions relatively simply with several steps to translate existing ecological response curves into functions suitable for economic analysis. First was harmonisation of $\mathrm{x}$-axes to total volume of water. The overall response of a complex organism like Golden Perch to flow regimes consists of separate sub-responses to different components of the flow regime - spawning from a spring high flow (fresh); survival of larvae from provision of shallow, slow flowing habitat over summer; and adult condition from provision of deep pools through autumn and winter. Each of these sub-responses was expressed graphically with ecological response on the $\mathrm{Y}$ axis, and total volume of environmental water used to achieve the response on the $\mathrm{X}$ axis. Having common units on the $\mathrm{X}$ axes allowed the three sub-responses to be combined for the economic analysis.

Second was harmonisation of y-axes to estimate population size. Strictly speaking, the sub-components listed above are realized as number of eggs produced, larval survivorship, and adult survivorship, respectively. For the economic analysis, these endpoints were translated to an estimate of impact on total population size - by translating previously held 'traffic light' (i.e. good, moderate, poor) outcome scores to estimates of the Golden Perch population from previous research carried out in the Goulburn-Broken catchment.

Third was translation of piece-wise linear functions to smooth equations. We translated those functions to smooth equations, allowing us to characterise the economic model in terms of marginal responses.

Fourth was the issue of combining sub-responses. A compound function for Golden Perch production was derived by assuming that the temporal periods for each of the sub-responses do not overlap. Therefore the overall production function is driven by spawning in spring, slow-flow habitat in summer, and pool habitat in autumn and winter. This assumption is untrue for real systems; however, within the bounds of our other uncertainties and simplifications, this assumption is minor.

The economic model maximises total social (defined here as environmental plus irrigation) benefits expressed in dollar equivalent terms for water allocation decisions. The total quantity of water available is limited, hence the economic problem for social welfare. Decisions are made for water allocations to environmental assets or endpoints, and agricultural outcomes.

The shadow price of water is derived for limited water shared between an environmental and agricultural use.

Keywords: Economic model, ecological responses, water allocations, Golden Perch, irrigated dairy 


\section{INTRODUCTION}

The Commonwealth of Australia (2007) enacted the Water Act 2007 to enable management of the MurrayDarling Basin water resources in the national interest. The Act gives effect to relevant international agreements and promotes the use and management of water resources to optimise economic, social and environmental outcomes. It establishes the Commonwealth Environmental Water Holder to administer Commonwealth environmental water. The Commonwealth Environmental Water Office (CEWO) has a framework for determining water use (CEWO, 2013) which requires that Commonwealth environmental water be used to maximise environmental outcomes, and that in developing environmental water options the ecological opportunity cost of water be considered.

Grafton et al. (2011) considered environmental and irrigation tradeoffs in making optimal dynamic water allocations in the Murray River. In their model the environmental impact of extended inter-flood periods was expressed as a drought cost, and the irrigation benefits (net profits) were expressed via an inverse demand function for irrigation water. Their model captured the dynamic, spatial and stochastic effects of water decisions at the Basin scale, but was highly aggregated in quantifying environmental and irrigation benefits. Bryan et al. (2013) integrated socioeconomic considerations with ecohydrology in mapping environmental flows. They derived social values to develop a total economic value for managing ecological assets and optimise environmental flow decisions. Horne et al. (2010) applied an economic framework to inform management of environmental entitlements using environmental response curves that allow the marginal benefit of water to the environment to be understood. They noted that this economic framework can also be used to describe trade between the environment and irrigators to achieve maximum social value by equating the marginal value of water to the environment and irrigators.

But even without trade, the economic framework can be conceptualised in making environmental flow decisions when water may be used for environmental or irrigation purposes. That is, if the ecological opportunity costs considered by the CEWO (2013) can be interpreted to include irrigated agriculture impacts, then the economic framework can provide information about marginal benefits and costs to the environment and agriculture in making water allocation decisions for social benefit.

This paper describes a catchment-level economic model for water allocation decisions for environmental and agricultural uses. A marginal economic framework is developed using ecological response curves and irrigation profits as they respond to water allocation decisions. The traditional economic framework is based on continuous, smooth, concave and differentiable responses. But ecological response functions may not be smooth or concave. Another aspect of this model is the valuation of ecological responses by social (dollar equivalent) values so that environmental and agricultural benefits are expressed in the same units. Other challenges include harmonising the $\mathrm{x}$-axis water decisions and the $\mathrm{y}$-axis ecological responses.

The model is developed for a simplified question of water allocation decisions for Golden Perch fish and irrigated dairy production in the Goulburn Valley of northern Victoria. For the purposes of this paper the essential features of the Goulburn Valley are shown in Figure 1. Lake Eildon is the major water storage, with water released downstream for both agricultural and environmental purposes. Goulburn Weir is a secondary regulating structure with irrigation water diverted either via the East Goulburn Main Channel to the Shepparton Irrigation District, or the Warranga Channel to the Warranga Basin for distribution to other irrigation areas. Irrigation water can also be released to the lower Goulburn River and thence to the Murray River. Environmental flow reaches 1-3 are above Goulburn Weir and do not house golden perch. The environmental focus of this analysis is the golden perch populations in reaches 4 and 5 downstream of Goulburn Weir.

\section{ECONOMIC FRAMEWORK}

The decision is how to allocate a quantity $(Q)$ of water in Lake Eildon, in any year, across different uses. In this model we simplify to 2 uses - an environmental $(E)$ allocation to promote Golden Perch fish populations and an irrigated $(I)$ agricultural allocation for milk production on dairy farms.

From Figure 1, irrigation uses, $I$, can be upstream $(U)$ or into the Murray $(M)$ in the summer irrigation season. The

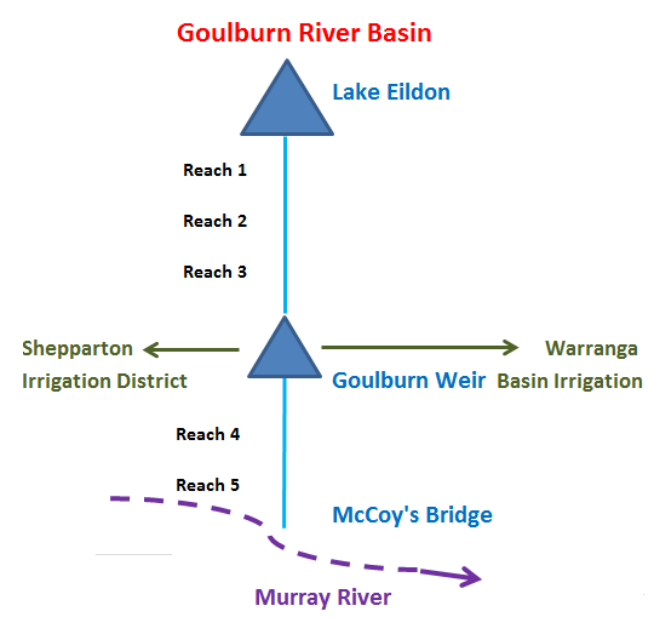

Figure 1. Schematic of the Goulburn Valley 
environmental uses, $E$, are in Reaches 4 and 5 and flows are in 'winter' (Apr-Sep; WI), 'spring' (Oct-Dec' $S P$ ) and 'summer' (Jan-Mar; $S U$ ), noting that these time periods do not match the austral seasons. We assume that most environmental summer (ESU) flows go into the Murray (IM). We also assume that watering decisions are made once only at the start of the year.

The uses of water are $Q i$, with $i=\{I U, I M, E W I, E S P$ and $E S U\}$. The task is to allocate an amount of water in Eildon $\bar{Q}$ within any year, where $\bar{Q}=\sum Q_{i}$. A common economic measure of social valuation is a market equivalent measure (Varian, 2014) of the value added by water applied, $Q i$, to the different uses. The value $(\mathrm{Vi})$, is:

$$
V i=P i . Q i,
$$

where, as before, $Q i$ is water allocated to each use, and $P i$ is the average price per unit of the $E$ or $I$ product produced per unit of $Q i$. The price $P i$ is assumed to be invariant to $Q i$. The problem is to choose $Q i$ to:

$$
\begin{aligned}
& \operatorname{Max} \sum P i . Q i, \\
& \text { subject to } \bar{Q}=\sum Q_{i} .
\end{aligned}
$$

The value functions are distinguished for the $E$ and $I$ uses. For $E$ water, environmental response functions $\left(E R_{i}\right)$ to water for Golden Perch are developed and an economic value for native fish in the Goulburn River catchment is used. For $I$ water, the value function is measured by irrigated dairy whole-farm profit $(\pi)$ determined with an optimising farm model reported by Farquharson et al. (2011). The value functions for water are:

$$
\begin{aligned}
& V_{I}=\pi_{I}=f(Q i), \text { and } \\
& V_{E}=\sum P i . E R i, \text { with } E R i=g(Q i) .
\end{aligned}
$$

The problem is to solve (1), (2) and (3). Algebraically this can be done by writing a Lagrangian function $L$ and solving (Silberberg, 1990) for $Q i$ :

$$
L=\sum V i+\lambda\left(\bar{Q}-\sum Q i\right)=\sum P i \cdot Q i+\lambda\left(\bar{Q}-\sum Q i\right) .
$$

For $I$ the first-order necessary condition is:

$$
d L / d Q i=M R i-\lambda=0, \text { or } M R_{I}=\lambda,
$$

where $M R i$ is the marginal revenue (change in $\pi$ ) from an incremental unit of water.

For $E$ the first-order necessary condition is:

$$
d L / d Q i=P i d E / d Q i-\lambda=0, \text { or } M R_{E}=\lambda .
$$

In this solution, $\lambda$ is the shadow price of an extra unit of water $Q$ when shared between uses. In the standard economic model the production functions are continuous, smooth, concave and differentiable. But in this case the ERi specified by river reach and seasons are not necessarily smooth or concave, hence the sufficient conditions are violated. Therefore numerical solution methods are used.

The quantity of water available for sharing in the Goulburn is initially set at 1,100 GL/year (CSIRO, 2008) and varied to generate water allocation decisions for different annual flows.

\section{ENVIRONMENTAL VALUATION}

Bennett et al. (2008) used Choice Modelling to develop the economic value of improved environmental health in three Victorian rivers. They designed and conducted surveys of river health attributes of native fish, riverside vegetation, native waterbirds and other animals, and water quality/recreational opportunities. The results were developed for human populations sampled within the catchment, out of the catchment and in Melbourne. Native fish responses were developed in terms of 'percentage of pre-settlement levels' based on information provided by experts in the field. The Golden Perch response functions to water decisions (below) were developed in these same environmental response units. Implicit prices for native fish were estimated to be $\$ 5$ per household per percentage point change in pre-settlement native fish population levels (native fish populations are currently at around $10 \%$ of pre-settlement levels), this is the stated preference willingness to pay for Golden Perch. 


\section{ECOLOGICAL AND AGRICULTURAL RESPONSES}

Flow components for Golden Perch are those currently included in environmental water management plans (e.g. Goulburn Broken Catchment Management Authority (GBCMA) (2015)). These components are (1) provision of spring freshes to promote spawning, (2) provision of shallow, slow-flowing 'slackwater' habitat to allow larvae to progress to young-of-year size (recruitment), and (3) provision of baseflow habitat year round to provide adult habitat. These responses are 'within-year', and don't take cumulative effects into account. However, we can consider the benefits of delivering these components year-in year-out for 20 years (the time frame over which the choice-modelling valuation was considered; Bennett et al. 2008), which ought to lead to a benefit. The provision of year-round baseflows can be simplified to the provision of baseflows during all months other than the ones when spawning flows or slackflows are desired (Table 1), as the baseflow component is built into the other components (see below).

If the flow component is delivered, it is assumed to be effective. Environmental water is assumed to have benefits downstream of Goulburn Weir (the mid-Goulburn between Goulburn Weir and Lake Eildon is highly-modified and does not support Golden Perch). We assume additivity of the responses (another simplification). This implies, for example that slackwater habitat is still valuable, even if a spawning flow is not delivered. We also assume that there are no transmission losses from Goulburn Weir to McCoy's Bridge.

The relevant priority flow components from the 2014/15 seasonal watering proposal (GBCMA, 2015) are in Table 2. We used the recommended discharge volumes to mark the point at which a flow component is fulfilled. We also used these figures to generate the response curve for spawning, combining the recommended flow peak with the required baseflow discharge. For slackwater and pool habitats, we employed existing empirical data relating discharge to slackwater and pool habitat provision (Webb et al. (2015)). Representations of the Table 1 flow components are in Figure 2.

Table 2. Priority flow components for Golden Perch (GBCMA 2015). Prescribed discharges are for the McCoy's Bridge gauging station in reach 5, near the bottom of the lower Goulburn River (Figure 1).

\begin{tabular}{|lllll|}
\hline Priority & Timing & Description & Endpoint & Objective \\
\hline 1 & Year & $540 \mathrm{ML} /$ day & Native fish & $\begin{array}{l}\text { Provide suitable in-channel habitat for all life } \\
\text { stages }\end{array}$ \\
5 & Oct-Dec & $\begin{array}{l}\text { As high as possible, up to } 15,000 \mathrm{ML} / \text { day, } \\
\text { with flows above } 5,600 \text { for } 2 \text { days }\end{array}$ & $\begin{array}{l}\text { Native fish } \\
\text { Initiate spawning, pre-spawning migrations } \\
\text { and recruitment of native fish }\end{array}$ \\
\hline
\end{tabular}

\subsection{Scaling of $y$ axes in response functions and summing benefits}

$\mathrm{Y}$ axes are in units of $\Delta \%$ improvement towards pre-European settlement fish assemblages (Bennett et al. 2008). We have assumed that meeting the flow recommendation for each individual component can result in a $10 \%$ improvement in the fish population over the 20 year timeframe. This assumption is based upon the personal experience of the authors, and known life history attributes of golden perch (e.g. 3-4 years to reach maturity, 20-25 year life span). The assumption recognizes that environmental flows alone are unlikely to restore fish populations to pre-settlement levels (i.e. achievement of all flows would result in $\sim 40 \%$ of the pre-European settlement assemblage over the 20 year timeframe). Each axis goes beyond $10 \%$ if the flow component is over-fulfilled. Assuming additivity, achievement of flow recommendations across all three flow components leads to a $30 \%$ increase in fish; this is probably slightly high, but is a simple place to start, and also recognizes that Golden Perch are not just limited by flow regulation. We have assumed simple additivity of the three functions despite the fact that the pools habitat is for 6 months of the year, and the others are each for 3 months. The assumption of equality across the three components is based upon the spawning and larval habitat being 'more important' for building the population than providing adult habitat.

\subsection{Spawning (Oct - Dec)}

Spawning flows call for a single flow event of peak magnitude and duration (Table 2). This is additional to base flow requirements for the remainder of the spawning period. We assume that the total volume released during this period respects minimum baseflow requirements, with the spawning peak on top of this. The total volume is a combination of unregulated inflows (a minor component), water released from Goulburn Weir to achieve baseflow recommendations for the three-month period, and water released from Goulburn Weir to create the spring fresh. 
We assume that effectiveness begins at 5,600 ML/d for 2 days, and maximises at 15,000 ML/d for 2 days, with the 'flow recommendation' being mid-way between these. This is conservative (spawning was observed at $4,000 \mathrm{ML} / \mathrm{d}$ in 2014). A piecewise linear function between these two extremes can be approximated using a logistic function (see Figure 2(a) and Table 3).

\subsection{Slackwater (Jan - Mar)}

Empirical data for slackwater (Webb et al. 2015) gives a non-monotonic function that would be very difficult to approximate with a smooth curve. The first four points can be well approximated with a parabola, with minimum habitat realized at $\sim 1,700 \mathrm{ML} / \mathrm{d}(\sim 150,000 \mathrm{ML}$ over 3 months). The function is constrained to not consider flows $>\sim 2,500 \mathrm{ML} / \mathrm{d}$ where slackwater habitat quickly drops to zero. The flow recommendation of $540 \mathrm{ML} / \mathrm{d}$ is towards the upper end of the curve. The estimated response is in Figure 2(b), see Table 3.

a) Effect of spawning flows

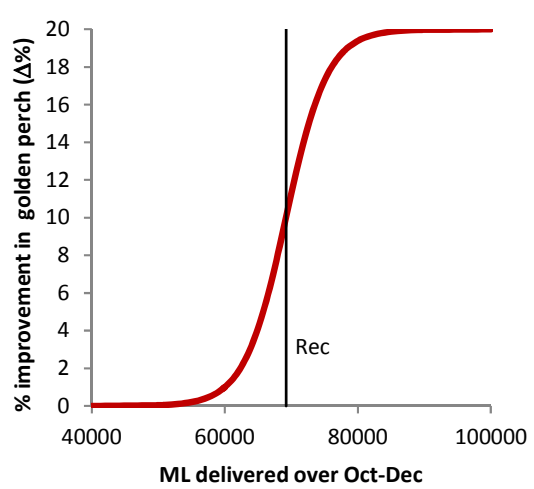

c) Effect of adult pool habitat

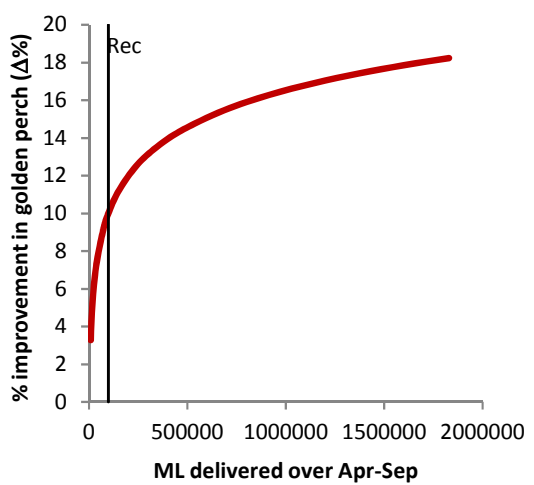

b) Effect of larval slackwater habitat

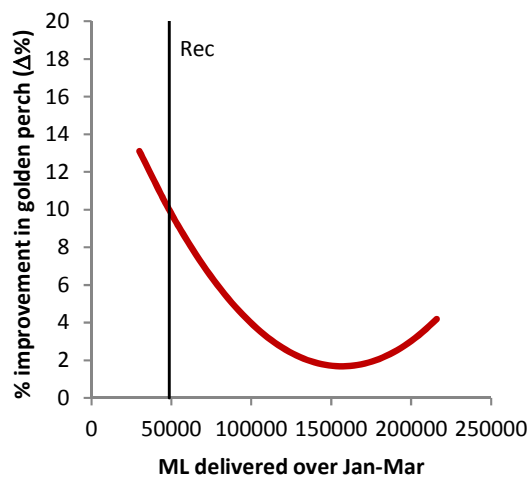

d) Catchment dairy income

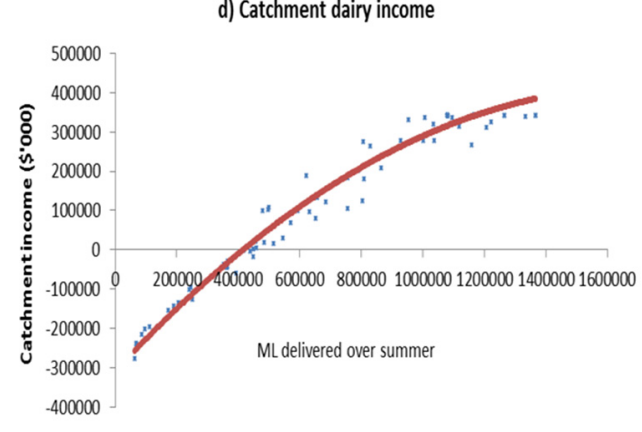

Figure 2. Ecological and agricultural response functions

Table 3. Environmental and agricultural response functions. Ecological parameters based upon Webb et al. (2015), with scaling and parameterization derived by applying these shapes to environmental flow delivery recommendations (GBCMA 2015). Agricultural response function drawn from Farquharson et al. (2011).

\begin{tabular}{|l|l|l|}
\hline Response & Equation & Parameters \\
\hline Spawning & Sigmoidal & $B_{\text {max }}$, maximum benefit, 20 \\
& $\Delta_{E S P}=B_{\max } /\left[1+\exp \left(-k\left(Q_{E S P}-Q_{0}\right)\right)\right]$ & $k$, slope steepness, 0.00032 \\
& & $Q_{0}$, volume for half benefit, 69,200 \\
\hline Slackwater & Quadratic & $a_{S L}, 7.118 \times 10^{-10}$ \\
& $\Delta_{E S U}=a_{S L} Q_{E S U}^{2}+b_{S L} Q_{E S U}+c_{S L}$ & $b_{S L},-2.231 \times 10^{-4}$ \\
& & $c_{S L}, 19.16$ \\
\hline Pools & $\log$ & $m_{p}$, multiplier, 2.823 \\
& $\Delta_{E W I}=m_{p} \cdot \ln \left(Q_{E W I}\right)+c_{p}$ & $c_{p}$, offset, -22.47 \\
& & $Q_{E W I}>5,000$ \\
\hline $\begin{array}{l}\text { Aggregate value of } \\
\text { increase in fish }\end{array}$ & $V_{E}=p_{H} H d\left(\Delta_{E S P}+\Delta_{E S U}+\Delta_{E W I}\right)$ & $p_{H, \text { percent of households willing to pay, 17 }}$ \\
\hline
\end{tabular}


Farquharson et al., Allocating limited water: linking ecology and economics

\begin{tabular}{|c|c|c|}
\hline \multicolumn{2}{|l|}{ population } & $\begin{array}{l}H, \text { total number of households, } 2.2 \times 10^{6} \\
d \text {, annualized social } \$ \text { value of } 1 \% \text { increase in } \\
\text { fish population, } \$ 150,000 \\
a_{D \mathrm{D}},--0.25 \times 10^{-6}, b_{D \mathrm{I}}, 0.8471\end{array}$ \\
\hline $\begin{array}{l}\text { Dairy farm } \\
\text { catchment income } \\
(\$)\end{array}$ & $\begin{array}{l}\text { Quadratic } \\
\mathrm{DFI}=a_{D I} Q_{I U}^{2}+b_{D I} Q_{I U}+c_{D I}\end{array}$ & $\begin{array}{l}a_{D \mathrm{I}},--0.25 \times 10^{-6}, b_{D \mathrm{I}}, 0.8471 \\
c_{D I},-3.09 \times 10^{5}\end{array}$ \\
\hline
\end{tabular}

\subsection{Pools (Apr - Sept)}

Empirical data for pool habitat is approximated by a log function, rising rapidly in lower parts of the curve, but more slowly as discharges become large (and the whole river effectively becomes deep water habitat). The fitted log function goes below zero as the water quantity approaches zero, and so a small constraint in acceptable solutions is required. Considerable benefit beyond that of the flow recommendation of $540 \mathrm{ML} / \mathrm{d}$ is possible if sufficient water is available. The estimated response is in Figure 2(c), see Table 3.

\subsection{Dairy farm responses}

Dairy farm responses were measured by irrigated dairy whole-farm profit $(\pi)$ determined with a Linear Programming (LP) (Pannell, 1997) farm model reported by Farquharson et al. (2011). Irrigated water supplies were modelled for 104 years and dairy farm-level profits maximised in each year in response to varying irrigation water supplies by selecting irrigated perennial and dryland pastures, and purchase of supplementary feed. The result was a series of dairy farm profits for each of 104 years of water supply.

\subsection{Value function estimation}

The agricultural value function (equation 3a) was developed by replotting the above series of annual dairy farm profits from years of lowest to highest water, and provides the agricultural response to varying water supplies. These profits developed through use of constrained optimisation (LP) are adapted responses to water decisions; hence the diminishing returns shape of the irrigation value function. The farm-level responses are aggregated through scaling according to the estimated number of dairy farms in the catchment (Montecillo (2006), HMC Property Group (2010)). A quadratic profit response function is fitted (Figure 2(d) and Table 3). The marginal revenue estimates for irrigated dairy are the change in profit per unit of water allocated to irrigation.

The ERi for Golden Perch (equation 3b), were developed in the same units as Bennett et al. (2008) percentage improvements in pre-settlement fish species and populations. The responses are considered to derive from delivering the water component decisions year-in year-out for 20 years, resulting in fish improvements over 20 years. The Bennett et al. (2008) price of $\$ 5 /$ household is the average willingness to pay for a 1 percentage point increased survival rate over that time period for the $17 \%$ households who responded to the survey. With an estimated 2.2 million households in Victoria at that time, this corresponds to a present value of $\$ 1.87$ million (2.2 million $\times 0.17 \times \$ 5)$. At 5\% p.a. discounted over 20 years, the annual value is $\$ 150,000$ per percentage point increase in fish survival.

\section{RESULTS AND CONCLUSIONS}

Figure 3(a) shows the (stacked) water allocation decisions for any given level of water in Eildon $(\bar{Q})$. This is a decision support framework given the socio-economic objective. Figure 3(b) shows the shadow price (value, $\$ / \mathrm{ML}$ ) of water as optimally allocated between Golden Perch and irrigated dairy production for each level of $\bar{Q}$. This is the value of an extra $\mathrm{ML}$ of water at each optimal decision, i.e. for each $\overline{\mathrm{Q}}$. As expected there is an inverse relationship between the shadow price and the amount of water to be allocated.

Other values for water (prices) are available from water trade between agricultural enterprises. But the shadow prices estimated here are different measures - the marginal value of water as optimally allocated between agricultural and ecological uses. These are the use and non-use values (Grafton et al. (2004)).

In conclusion the model presented here is an illustration of an economic-ecological approach to making water allocation decisions within a river catchment. The model includes only one ecological and one economic use of water - hence the results are preliminary and can be further developed. 
Farquharson et al., Allocating limited water: linking ecology and economics
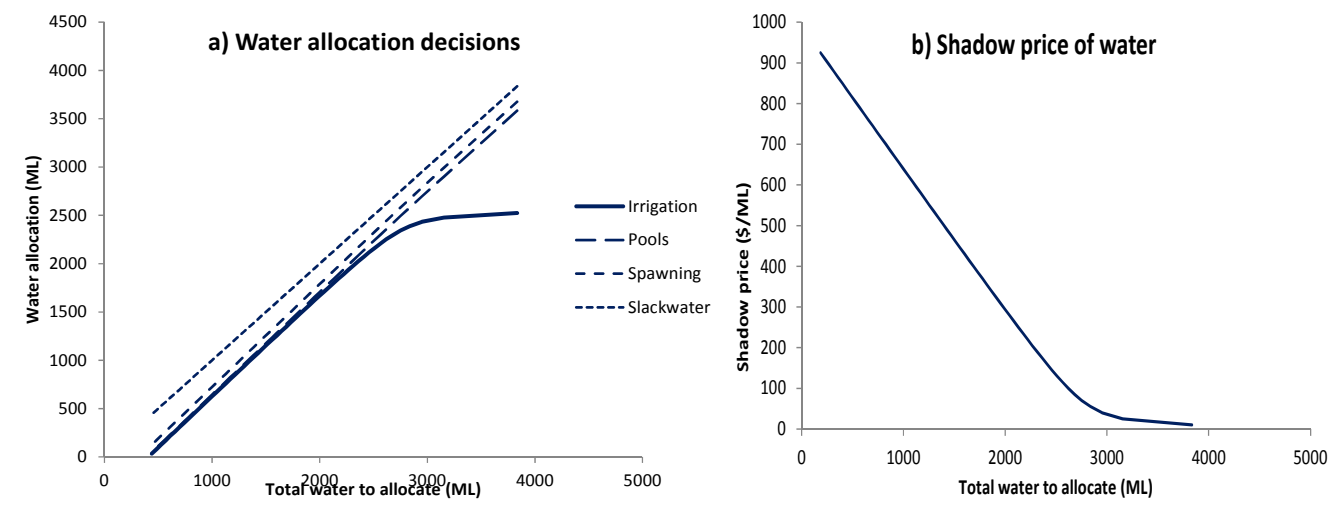

Figure 3. Water allocation decisions and shadow price of water

The paper is innovative in using an economic framework including agricultural and ecological responses to water decisions in representing social welfare, by including social willingness to pay estimates for enhanced fish populations, in developing ecological responses in terms of the units relating to the willingness to pay estimates for native fish, and in coordinating the units for $\mathrm{x}$ - and $\mathrm{y}$-axis measures. However, there are a number of major simplifying assumptions made to specify and solve the model, including use of continuous and smooth forms for piecewise linear functions. The model can be further developed for decision analysis.

\section{REFERENCES}

Bennett, J., Dumsday, R., Howell, G., Lloyd, C., Sturgess, N., \& Van Raalte, L. (2008). The economic value of improved environmental health in Victorian rivers. Australasian Journal of Environmental Management, 42(2), 131-148.

Bryan, B. A., Higgins, A., Overton, I. C., Holland, K., Lester, R. E., King, D., . . Kirby, M. (2013). Ecohydrological and socioeconomic integration for the operational management of environmental flows. Ecological Applications, 23(5), 999-1016. doi:10.1890/12-2104.1

CEWO. (2013). Framework for Determining Commonwealth Environmental Water Use. Retrieved from Canberra, May:

Commonwealth of Australia. (2007). Water Act 2007. Retrieved from Canberra, http://www.comlaw.gov.au: http://www.comlaw.gov.au

CSIRO. (2008). Water availability in the Goulburn-Broken. A report to the Australian Government from the CSIRO Murray-Darling Sustainable Yields project. Retrieved from CSIRO, Australia, 132pp:

Farquharson, R., Ramilan, T., Stewardson, M., Beverley, C., Vietz, G., George, B., . . Sammonds, M. (2011). Water sharing for the environment and agriculture in the Broken catchment. Paper presented at the 55th Annual Conference of the Australian Agricultural and Resource Economics Society, Melbourne, 8-11 February.

GBCMA. (2015). Goulburn River Seasonal Watering Proposal 2014-2015. Retrieved from Shepparton:

Grafton, R. Q., Adamowicz, W., Pupont, D., Nelson, H., Hill, R.J., Renzetti, S. (2004). The economics of the environment and natural resources. Carlton, Victoria Australia: Blackwell Publishing.

Grafton, R. Q., Chu, H. L., Stewardson, M., \& Kompas, T. (2011). Optimal dynamic water allocation: Irrigation extractions and environmental tradeoffs in the Murray River, Australia. Water Resources Research, 47.

HMC Property Group. (2010). Changing Land Use in the GMID 20006-2010: Where have all the dairies gone? Retrieved from

Horne, A., Stewardson, M., Freebairn, J., \& McMahon, T. A. (2010). Using an economic framework to inform management of environmental entitlements. River Research and Applications, 26, 779-795.

Montecillo, O. (2006). Socio-Economic Profile of the Goulburn Broken Catchment. Retrieved from Shepparton Victoria 3660:

Pannell, D. J. (1997). Practical Linear Programming. New York: John Wiley and Sons.

Silberberg, E. (1990). The Structure of Economics, A Mathematical Approach. New Jersey: Englewood Cliffs.

Varian, H. R. (2014). Intermediate Microeconomics: A Modern Approach Ninth Edition. New York: Norton.

Webb, A., Vietz, G., Windecker, S., Hladyz, S., Thompson,R., Koster, W., Jones, M. (2015). Monitoring and reporting on the ecological outcomes of commonwealth environmental water delivered in the lower Goulburn River and Broken Creek in 2013/14. Retrieved from Melbourne, ISBN 978073405112 7: 